\title{
Exploring Kaposi's sarcoma-associated herpesvirus latent genes' role in viral lymphomagenesis using transgenic mice
}

\section{S-H Sin*, FD Fakhari and DP Dittmer}

Address: Department of Microbiology and Immunology and Lineberger comprehensive Cancer Center, The University of North Carolina at Chapel Hill, Chapel Hill, North Carolina, USA

* Corresponding author

from I I th International Conference on Malignancies in AIDS and Other Acquired Immunodeficiencies (ICMAOI): Basic, Epidemiologic, and Clinical Research

Bethesda, MD, USA. 6-7 October 2008

Published: 17 June 2009

Infectious Agents and Cancer 2009, 4(Suppl 2):P39 doi:10.1 186/1750-9378-4-S2-P39

This abstract is available from: http://www.infectagentscancer.com/content/4/S2/P39

(c) 2009 Sin et al; licensee BioMed Central Ltd.

Kaposi's sarcoma-associated herpesvirus (KSHV) is a human lymphotropic gammaherpesvirus and associated with Kaposi sarcoma as well as two B cell lymphoproliferative disorders: primary effusion lymphoma (PEL) and multicentric Castleman disease. We reported that the KSHV latency-associated nuclear antigen (LANA) transgenic mice developed splenic follicular hyperplasia and showed increased germinal center formation. Here we report that the KSHV LANA-induced B cell activation is CD19 dependent and LANA restores the marginal zone defect in CD19-/- mice. To test KSHV latent genes' role in viral lymphomagenesis, we generated mice expressing all KSHV latency-associated genes. All of the transgenic mice induced mature B cell activation. Further characterization of the mice expressing all KSHV latency-associated genes is currently underway. 